\title{
Risks and seasonal pattern for mortality among hospitalized infants in a conflict-affected area of Pakistan, 2013-2016. A
} retrospective chart review. [version 1; peer review: 2 approved, 1 approved with reservations]

\section{Babette van Deursen (iD) , Annick Lenglet (DiD1,2, Cono Ariti33, Barkat Hussain (iD) Jaap Karsten ${ }^{1}$, Harriet Roggeveen ${ }^{1}$, Debbie Price ${ }^{1}$, Jena Fernhout ${ }^{1}$, Ahmed Abdi ${ }^{5}$, Antonio Isidro Carrion Martin (iD 6}

\footnotetext{
${ }^{1}$ Médecins Sans Frontières - Operational Centre Amsterdam, Amsterdam, The Netherlands

${ }^{2}$ Radboud University Nijmegen Medical Centre, Nijmegen, The Netherlands

${ }^{3}$ Cardiff University Medical School, Cardiff, UK

${ }^{4}$ Pediatric Division Head Quarter-Ministry of Health, Balochistan, Pakistan

${ }^{5}$ Médecins Sans Frontières - Pakistan, Balochistan, Pakistan

${ }^{6}$ Médecins Sans Frontières - UK, London, UK
}

\begin{tabular}{l}
\hline V1 First published: 24 Jun 2019, 8:954 \\
https://doi.org/10.12688/f1000research.19547.1 \\
Latest published: 24 Jun 2019, 8:954 \\
https://doi.org/10.12688/f1000research.19547.1 \\
\hline
\end{tabular}

\section{Abstract}

Background: In recent years, Médecins Sans Frontières has observed high mortality rates among hospitalized infants in Pakistan. We describe the clinical characteristics of the infants admitted between 2013 and 2016 in order to acquire a better understanding on the risk factors for mortality.

Methods: We analyzed routinely collected medical data from infants ( $<7$ months) admitted in Chaman and Dera Murad Jamali (DMJ) hospitals. The association between clinical characteristics and mortality was estimated using Poisson regression.

Results: Between 2013 and 2016, 5,214 children were admitted (male/female ratio: 1.60) and 1,178 (23\%) died. Days since admission was associated with a higher risk of mortality and decreased with each extra day of admission after seven days. The first 48 hours of admission was strongly associated with a higher risk of mortality. A primary diagnosis of tetanus, necrotizing enterocolitis, prematurity, sepsis and hypoxic-ischemic encephalopathy were strongly associated with higher rates of mortality. We observed an annual peak in the mortality rate in September.

Conclusions: The first days of admission are critical for infant survival. Furthermore, the found male/female ratio was exceedingly higher than the national ratio of Pakistan. The observed seasonality in mortality rate by week has not been previously reported. It is fully
Open Peer Review

\begin{tabular}{cccc} 
Approval Status & $?$ & \\
& 1 & 2 & 3 \\
\hline version 1 & $?$ & & \\
24 Jun 2019 & view & view & view
\end{tabular}

1. Babar Tasneem Shaikh iD, Health Services Academy, Islamabad, Pakistan

2. Eva Leidman (D), Centers for Disease Control and Prevention, Atlanta, USA

3. Sharif Ismail ID, Imperial College London, London, UK London School of Hygiene and Tropical Medicine, London, UK

Any reports and responses or comments on the article can be found at the end of the article. 
recommended to do further in-depth research on male/female ratio differences and the reasons behind the annual peaks in mortality rate by week.

Keywords

Infant mortality; Epidemiology; Seasonal pattern; Pakistan; MSF

This article is included in the Médecins Sans

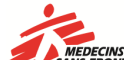

Frontières gateway.

Corresponding author: Babette van Deursen (babettevandeursen@hotmail.com)

Author roles: van Deursen B: Conceptualization, Formal Analysis, Supervision, Visualization, Writing - Original Draft Preparation, Writing - Review \& Editing; Lenglet A: Conceptualization, Formal Analysis, Project Administration, Supervision, Validation, Writing Original Draft Preparation, Writing - Review \& Editing; Ariti C: Formal Analysis, Supervision, Validation, Writing - Review \& Editing; Hussain B: Validation, Writing - Review \& Editing; Karsten J: Validation, Writing - Review \& Editing; Roggeveen H: Validation, Writing Review \& Editing; Price D: Validation, Writing - Review \& Editing; Fernhout J: Project Administration, Validation, Writing - Review \& Editing; Abdi A: Project Administration, Validation, Writing - Review \& Editing; Carrion Martin AI: Formal Analysis, Supervision, Validation, Writing - Original Draft Preparation, Writing - Review \& Editing

Competing interests: No competing interests were disclosed.

Grant information: The author(s) declared that no grants were involved in supporting this work.

Copyright: ( 2019 van Deursen B et al. This is an open access article distributed under the terms of the Creative Commons Attribution License, which permits unrestricted use, distribution, and reproduction in any medium, provided the original work is properly cited.

How to cite this article: van Deursen $B$, Lenglet $A$, Ariti $C$ et al. Risks and seasonal pattern for mortality among hospitalized infants in a conflict-affected area of Pakistan, 2013-2016. A retrospective chart review. [version 1; peer review: 2 approved, 1 approved with reservations] F1000Research 2019, 8:954 https://doi.org/10.12688/f1000research.19547.1

First published: 24 Jun 2019, 8:954 https://doi.org/10.12688/f1000research.19547.1 


\section{List of abbreviations:}

95\% CI $95 \%$ Confidence Intervals

aRR Adjusted Rate Ratio

DHS Demographic and Health Survey

DMJ Dera Murad Jamali

HIE Hypoxic-ischemic Encephalopathy

$\mathrm{MoH} \quad$ Ministry of Health

MSF Médecins Sans Frontières

MSF-OCA Médecins Sans Frontières Operational Centre Amsterdam

\section{NEC Necrotizing Enterocolitis}

RR

Rate Ratio

\section{Introduction}

As part of the Millennium Development Goals, the under-five mortality (U5M) should be reduced by two-thirds from 1990 to $2015^{1,2}$. In 2015 , the U5M was reportedly 47 per 1,000 live births in low resource settings compared to 6 per 1,000 live births in high resource countries ${ }^{2}$. Mortality in children under five is still high in Southern Asia compared to other regions. In Pakistan, the Demographic and Health Survey (DHS) of 2012-13 showed that mortality among neonates and infants was still one of highest in South Asia. Especially in the Balochistan region, where the neonatal mortality was 55 deaths per 1,000 live births and under-five mortality was 111 deaths per 1,000 live births ${ }^{3}$.
Médecins Sans Frontières works in cooperation with the Ministry of Health $(\mathrm{MoH})$ in two hospitals in the Balochistan province of Pakistan ${ }^{4}$. Balochistan is an unstable and vulnerable province due to historical disputes between different (ethnic) groups (Figure 1) $)^{5}$. One of the hospitals is located in Chaman, in the north of Balochistan near the Afghan border. The Chaman project offers services to the residents, to Afghan refugees and also to Afghans crossing the border in search of medical services. The second hospital is located in the southern region of Balochistan in Dera Murad Jamali (DMJ). This hospital offers services to the residents of Nasirabad and Jafarabad districts.

In recent years, MSF has observed high in-hospital mortality among neonates and infants in both Chaman and DMJ hospitals. Since 2010, the recorded monthly neonatal mortality (neonatal deaths amongst all neonatal exits from the neonatal department) has exceeded $25 \%$ in both hospitals (MSF unpublished data). In order to better understand the causes for mortality and provide recommendations for clinical care, we aimed to describe the clinical characteristics of the infants under seven months admitted between 2013 and 2016 Chaman and DMJ hospitals.

\section{Methods}

Design

This study consisted of secondary retrospective analysis of routinely collected data in the neonatal departments of DMJ and Chaman hospitals. The clinical characteristics available for analysis were: sex, date of admission and exit (discharge or death), primary diagnosis, and outcome (i.e. death or alive). We were only able to classify patients in two age groups, under seven

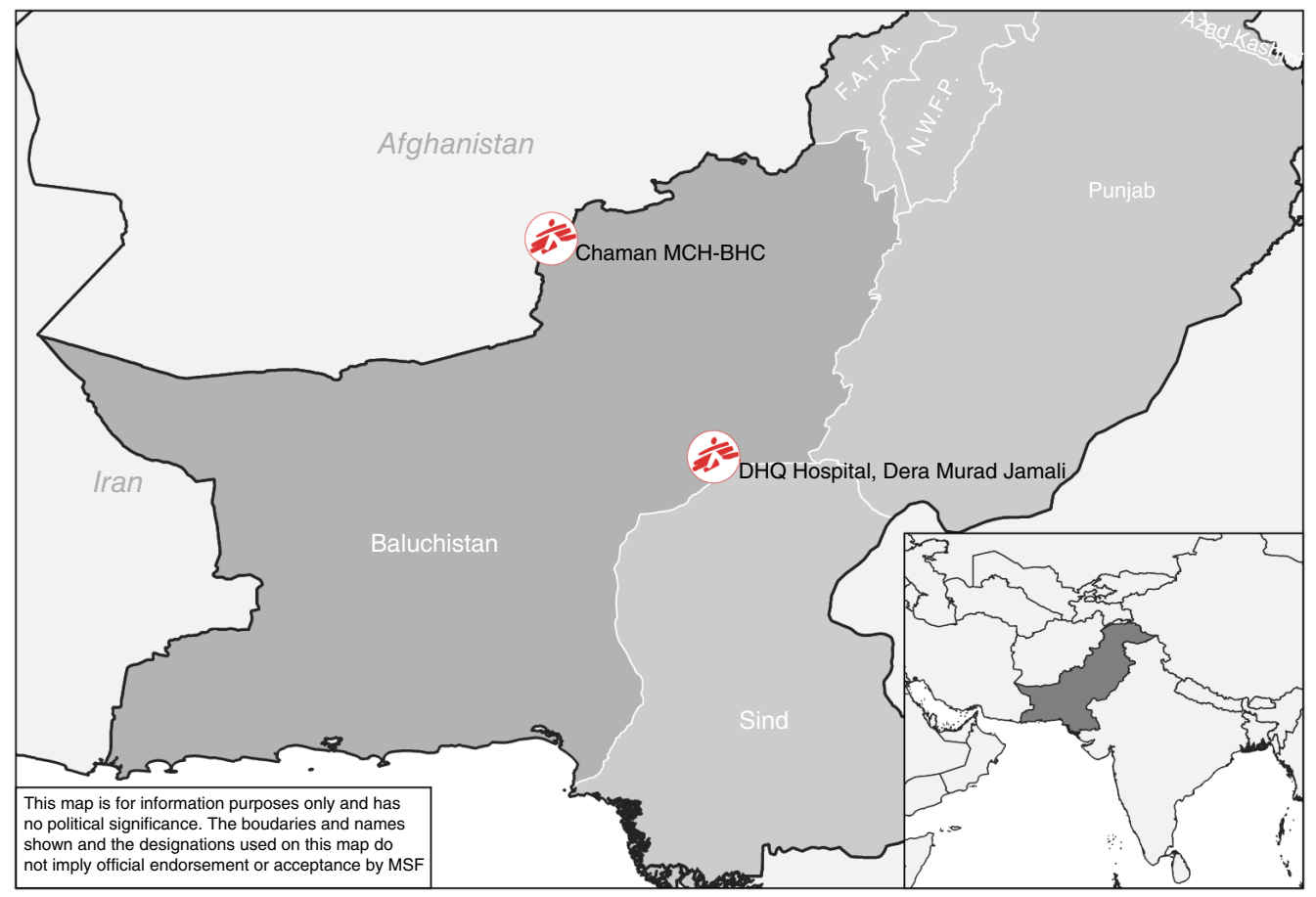

Figure 1. Projects of Médecins Sans Frontières (MSF) in Pakistan. Author: MSF UK Data Source: Natural Earth; MSF 
months and greater or equal to seven months. Thus, no specific ages were available for more refined analyses on age of infants.

\section{Study population and setting}

All children younger than seven months old admitted to the DMJ and Chaman hospital between 2013 and 2016 were included in this study. Patients, for whom crucial data was missing such as exit date and primary diagnosis, were excluded from this study.

\section{Statistical analysis}

All data was extracted and anonymized before the analysis. We calculated an exposure time (person days) for each patient by subtracting their date of admission from the date of discharge. The primary diagnosis was categorized into sepsis, neonatal tetanus, necrotizing enterocolitis (NEC), prematurity, hypoxicischemic encephalopathy (HIE), maternal-fetal infection, respiratory syndromes and other. Those were chosen due to the high frequency of reported diagnosis and other contained the remaining diagnoses.

The mortality rate by month was calculated with their corresponding 95\% CI and a two-months-moving-average was used to explore seasonality.

We used Poisson regression to calculate the unadjusted Rate Ratios (RRs) with their respective 95\% confidence intervals (95\% CI) and p-values to assess the association of each possible risk factor with the outcome of in-hospital mortality. For the primary diagnosis, we used respiratory syndromes as the reference group as it had lowest mortality rate and a sufficient number of events. A Poisson multivariable regression model was used to calculate adjusted RRs (aRR) with their corresponding 95\% CI and p-values. Each patient's exposure time was split into single day periods and this elapsed time variable was included in the Poisson models to estimate the mortality rate, rate ratios, $95 \%$ CIs and $\mathrm{p}$-values for each day since admission.

The data cleaning and manipulation was done using Excel 2010, and data analysis was done using Stata IC 146. We did not merge the datasets from the two hospitals, because it would be more useful for the teams as the two hospitals contexts were different and presenting merged results may have diluted the specificities in the particular situations each team faces.

Ethical consideration: This was a retrospective post-hoc analysis of routinely collected clinical data; therefore, it was exempted from MSF ethical board review. The MSF-OCA medical director gave his approval for this analysis. The data in the utilized datasets did not contain individual identifiers and it was password protected and only accessible by the research team.

\section{Results}

Chaman

Between 2013 and 2016, there were 2,551 infants admitted in the Inpatient Department (IPD) of Chaman, 563 (22\%) of them died (Table 1). There were more males admitted $(n=1,573)$ than females $(n=977)$; the male to female ratio was 1.61 . The diagnosis NEC and HIE were responsible for the highest mortality rates (Table 2).

In the adjusted analysis (Table 1), the number of days since admission was strongly associated with a higher risk of mortality when compared to day eight or more days since admission. The highest risks for mortality were observed during the first five days since admission and decreased after that with each extra day of admission: at day 5 aRR=5.20 (95\% CI: 3.34-8.08) and at day 8 aRR=1.28 (95\% CI: 0.57-2.91). Furthermore, some primary clinical diagnoses were also associated with mortality compared to a diagnosis of respiratory syndromes, namely: NEC $(\mathrm{aRR}=5.79 ; 95 \% \mathrm{CI}: 3.20-10.48)$, prematurity (aRR=3.41; 95\% CI: 2.39-4.86), HIE $\quad(\mathrm{aRR}=3.25 ; 95 \%$ CI: $2.29-4.61)$ and suspected clinical sepsis $(\mathrm{aRR}=2.11 ; 95 \%$ CI: $1.50-2.98)$.

\section{DMJ}

Between 2013 and 2015, there were 2,663 infants admitted in the IPD and $23 \%(n=615)$ died during their admission (Table 3). More males $(n=1,636)$ were admitted than females $(n=1,207)$; the male/female ratio was 1.59 . The primary diagnosis tetanus, NEC, HIE and sepsis had the highest mortality rates (Table 4).

In the adjusted analysis (Table 3), the number of days since admission was strongly associated with death and with each extra day in the hospital this risk decreased when compared to day eight or more since admission: at day one aRR $=13.38(95 \%$ CI: 9.14-19.59) and at day eight $\mathrm{aRR}=1.72$ (95\% CI:0.79-3.73). In addition, patients with one of the following diagnosis had an increased risk for death versus a diagnosis of respiratory syndrome: suspected neonatal tetanus $(\mathrm{aRR}=8.50 ; 95 \% \mathrm{CI}$ : 5.88-12.29), NEC (aRR=11.65; 95\% CI: 4.56-29.76), HIE $(\mathrm{aRR}=4.13 ; \quad 95 \% \quad \mathrm{CI}: \quad 2.97-5.75), \quad$ sepsis $\quad(\mathrm{aRR}=3.43 ; \quad 95 \%$ CI: $2.47-4.76)$ and prematurity $(\mathrm{aRR}=3.32 ; 95 \% \mathrm{CI}: 2.33-4.72)$.

\section{Seasonality}

We observed an annual peak in the mortality rate between July and October in both hospitals with the mortality rate peaking in September. On average, the two-months-moving-average of the mortality rate was 40 per 1,000 person days (exposure time) for Chaman. The annual peaks in Chaman had a mortality rate that varied between 40-100 per 1,000 person days (Figure 2). For DMJ, the two-months-moving average was on average around 30 per 1000 person days. The mortality rates in the annual peaks varied between 40-70 per 1,000 person days (Figure 3). There was considerable month to month variation in mortality rates as can be observed from the 95\% CIs shown in Figure 2 and Figure 3. Smoothing these crude rates using a two-month moving average still showed some evidence of an annual peaks.

\section{Discussion}

We found that the mortality in children under seven months age was $23 \%$ in two hospitals in Balochistan province in Pakistan between 2013 and 2016. In both hospitals, the number of days since admission was strongly associated with death: 
Table 1. Patient characteristics and analysis results of the infants ( $<7$ months) who were admitted between 2013 and 2016 in the Inpatient Department (IPD) of Chaman.

\begin{tabular}{|c|c|c|c|c|c|c|}
\hline Characteristics & $\begin{array}{l}\text { Admitted } \\
(\mathrm{n}=2,551)\end{array}$ & $\begin{array}{l}\text { Died } \\
(n=563)\end{array}$ & $\begin{array}{l}\text { Unadjusted Rate } \\
\text { Ratios }[95 \% \mathrm{Cl}]\end{array}$ & P-value & $\begin{array}{l}\text { Adjusted Risk } \\
\text { Ratios [95\%Cl] }\end{array}$ & P-value \\
\hline $\begin{array}{l}\text { Female } \\
\text { Male } \\
\text { Unknown }\end{array}$ & $\begin{array}{l}977 \\
1,573 \\
1\end{array}$ & $\begin{array}{l}211(21.6 \%) \\
351(22.3 \%) \\
1(100 \%)\end{array}$ & $\begin{array}{l}0.95[0.80-1.13] \\
\text { Ref. } \\
-\end{array}$ & $\begin{array}{l}0.564 \\
- \\
-\end{array}$ & $\begin{array}{l}0.94[0.79-1.12] \\
\text { Ref. } \\
-\end{array}$ & 0.505 \\
\hline $\begin{array}{l}\text { Year of admission } \\
\qquad \begin{array}{r}2013 \\
2014 \\
2015 \\
2016\end{array}\end{array}$ & $\begin{array}{l}511 \\
682 \\
635 \\
723\end{array}$ & $\begin{array}{l}111(21.7 \%) \\
176(25.8 \%) \\
138(21.7 \%) \\
138(19.1 \%)\end{array}$ & $\begin{array}{l}\text { Ref. } \\
1.44[1.13-1.82] \\
1.21[0.94-1.56] \\
1.12[0.87-1.44]\end{array}$ & 0.019 & $\begin{array}{l}\text { Ref. } \\
1.56[1.14-2.14] \\
1.30[0.98-1.73] \\
1.28[0.95-1.71]\end{array}$ & 0.048 \\
\hline $\begin{array}{l}\text { Month of admission } \\
\text { January } \\
\text { February } \\
\text { March } \\
\text { April } \\
\text { May } \\
\text { June } \\
\text { July } \\
\text { August } \\
\text { September } \\
\text { October } \\
\text { November } \\
\text { December }\end{array}$ & $\begin{array}{l}240 \\
219 \\
220 \\
206 \\
189 \\
210 \\
202 \\
221 \\
208 \\
215 \\
228 \\
193\end{array}$ & $\begin{array}{l}54(22.5 \%) \\
47(21.5 \%) \\
50(22.7 \%) \\
42(20.4 \%) \\
30(15.9 \%) \\
38(18.1 \%) \\
48(23.8 \%) \\
46(20.8 \%) \\
73(35.1 \%) \\
47(21.9 \%) \\
42(18.4 \%) \\
46(23.8 \%)\end{array}$ & $\begin{array}{l}\text { Ref. } \\
1.05[0.71-1.56] \\
1.02[0.70-1.50] \\
0.97[0.65-1.45] \\
0.71[0.45-1.11] \\
0.83[0.55-1.26] \\
1.18[0.80-1.74] \\
1.02[0.69-1.51] \\
2.05[1.44-2.92] \\
1.03[0.70-1.52] \\
0.86[0.57-1.28] \\
1.36[0.92-2.01]\end{array}$ & $<0.001$ & $\begin{array}{l}\text { Ref. } \\
0.83[0.56-1.24] \\
0.95[0.64-1.39] \\
0.81[0.53-1.24] \\
0.59[0.38-0.92] \\
0.62[0.41-0.96] \\
0.87[0.58-1.30] \\
0.75[0.50-1.12] \\
1.38[0.95-2.02] \\
0.87[0.58-1.28] \\
0.76[0.51-1.14] \\
1.23[0.83-1.82]\end{array}$ & 0.001 \\
\hline $\begin{array}{l}\text { Number of days since admission } \\
0 \text { days } \\
1 \text { day } \\
2 \text { days } \\
3 \text { days } \\
4 \text { days } \\
5 \text { days } \\
6 \text { days } \\
7 \text { days } \\
8 \text { days } \\
>8 \text { days }\end{array}$ & $\begin{array}{l}226 \\
245 \\
336 \\
347 \\
339 \\
212 \\
181 \\
134 \\
90 \\
441\end{array}$ & $\begin{array}{l}85(37.6 \%) \\
127(51.8 \%) \\
84(25.0 \%) \\
49(14.1 \%) \\
63(18.6 \%) \\
53(25.0 \%) \\
38(21.0 \%) \\
25(18.7 \%) \\
7(7.8 \%) \\
32(7.3 \%)\end{array}$ & $\begin{array}{l}2.75[1.83-4.13] \\
4.60[3.12-6.78] \\
3.63[2.42-5.45] \\
2.64[1.69-4.13] \\
4.49[2.94-6.88] \\
4.73[3.05-7.34] \\
4.32[2.70-6.92] \\
3.57[2.11-6.02] \\
1.20[0.53-2.73] \\
\text { Ref. }\end{array}$ & $<0.001$ & $\begin{array}{l}3.11[2.06-4.68] \\
5.20[3.52-7.69] \\
4.03[2.67-6.08] \\
2.93[1.87-4.59] \\
4.91[3.20-7.53] \\
5.20[3.34-8.08] \\
4.72[2.94-7.56] \\
3.85[2.28-6.50] \\
1.28[0.57-2.91] \\
\text { Ref. }\end{array}$ & $<0.001$ \\
\hline $\begin{array}{l}\text { Bed occupancy rate } \\
\qquad \begin{array}{c}0-85 \% \\
>85 \%\end{array}\end{array}$ & $\begin{array}{l}949 \\
1,602\end{array}$ & $\begin{array}{l}225(23.7 \%) \\
338(21.1 \%)\end{array}$ & $\begin{array}{l}\text { Ref. } \\
0.95 \text { [0.80-1.12] }\end{array}$ & - & $\begin{array}{l}\text { Ref. } \\
0.85 \text { [0.67-1.08] }\end{array}$ & 0.187 \\
\hline $\begin{array}{l}\text { Primary diagnosis } \\
\text { Sepsis } \\
\text { NEC } \\
\text { HIE } \\
\text { Prematurity } \\
\text { Respiratory syndromes } \\
\text { Other }\end{array}$ & $\begin{array}{l}803 \\
18 \\
437 \\
273 \\
468 \\
552\end{array}$ & $\begin{array}{l}190(23.7 \%) \\
15(83.3 \%) \\
142(32.5 \%) \\
118(43.2 \%) \\
43(9.2 \%) \\
55(10.0 \%)\end{array}$ & $\begin{array}{l}1.99[1.43-2.77] \\
5.47[3.04-9.84] \\
3.01[2.14-4.24] \\
2.71[1.91-3.85] \\
\text { Ref. } \\
1.11[0.74-1.65]\end{array}$ & $<0.001$ & $\begin{array}{l}2.11[1.50-2.98] \\
5.79[3.20-10.48] \\
3.25[2.29-4.61] \\
3.41[2.39-4.86] \\
\text { Ref. } \\
1.16[0.78-1.73]\end{array}$ & $\begin{array}{l}<0.001 \\
-\end{array}$ \\
\hline
\end{tabular}

Table 2. Mortality rates per 1,000 person days $(95 \% \mathrm{Cl})$ for the primary diagnoses in Chaman.

\begin{tabular}{|l|l|}
\hline Primary diagnosis & $\begin{array}{l}\text { Mortality rates per } \mathbf{1 , 0 0 0} \\
\text { person days } \mathbf{( 9 5 \%} \mathbf{~ C l )}\end{array}$ \\
\hline NEC & $114.50(69.03-189.93)$ \\
Sepsis & $41.59(36.08-47.95)$ \\
HIE & $63.05(53.49-74.33)$ \\
Prematurity & $56.79(47.41-68.01)$ \\
Respiratory syndromes & $20.93(15.53-28.23)$ \\
Other & $23.17(17.79-30.18)$ \\
\hline
\end{tabular}

NEC - necrotizing enterocolitis, HIE - hypoxic-ischemic encephalopathy 
Table 3. Patient characteristics and analysis results of the infants ( $<7$ months) who were admitted between 2013 and 2016 in the Inpatient Department (IPD) of Dera Murad Jamali (DMJ).

\begin{tabular}{|c|c|c|c|c|c|c|}
\hline Characteristics & $\begin{array}{l}\text { Admitted } \\
(n=2,663)\end{array}$ & $\begin{array}{l}\text { Died } \\
(n=615)\end{array}$ & $\begin{array}{l}\text { Unadjusted } \\
\text { Rate Ratio } \\
{[95 \% \mathrm{Cl}]}\end{array}$ & P-value & $\begin{array}{l}\text { Adjusted } \\
\text { Rate Ratio } \\
{[95 \% \mathrm{Cl}]}\end{array}$ & P-value \\
\hline $\begin{array}{l}\text { Female } \\
\text { Male }\end{array}$ & $\begin{array}{l}1,027 \\
1,636\end{array}$ & $\begin{array}{l}241(23.5 \%) \\
374(22.9 \%)\end{array}$ & $\begin{array}{l}1.05 \text { [0.89-1.24] } \\
\text { Ref. }\end{array}$ & 0.542 & $\begin{array}{l}1.10[0.93-1.30] \\
\text { Ref. }\end{array}$ & 0.254 \\
\hline $\begin{array}{l}\text { Year of admission } \\
\qquad \begin{array}{r}2013 \\
2014 \\
2015 \\
2016\end{array}\end{array}$ & $\begin{array}{l}743 \\
742 \\
595 \\
583\end{array}$ & $\begin{array}{l}147(19.8 \%) \\
170(22.9 \%) \\
158(26.6 \%) \\
140(24.0 \%)\end{array}$ & $\begin{array}{l}\text { Ref. } \\
1.04[0.83-1.30] \\
0.95[0.76-1.19] \\
0.87[0.69-1.10]\end{array}$ & 0.446 & $\begin{array}{l}\text { Ref. } \\
0.91[0.71-1.16] \\
0.94[0.74-1.19] \\
0.80[0.63-1.03]\end{array}$ & 0.384 \\
\hline $\begin{array}{l}\text { Month of admission } \\
\text { January } \\
\text { February } \\
\text { March } \\
\text { April } \\
\text { May } \\
\text { June } \\
\text { July } \\
\text { August } \\
\text { September } \\
\text { October } \\
\text { November } \\
\text { December }\end{array}$ & $\begin{array}{l}241 \\
228 \\
213 \\
198 \\
181 \\
166 \\
217 \\
238 \\
273 \\
268 \\
251 \\
189\end{array}$ & $\begin{array}{l}53(22.0 \%) \\
52(22.8 \%) \\
43(20.2 \%) \\
40(20.2 \%) \\
47(26.0 \%) \\
29(17.5 \%) \\
47(21.7 \%) \\
58(24.4 \%) \\
80(29.3 \%) \\
72(26.9 \%) \\
57(22.7 \%) \\
37(19.6 \%)\end{array}$ & $\begin{array}{l}\text { Ref. } \\
1.01[0.69-1.48] \\
0.90[0.61-1.35] \\
0.84[0.56-1.27] \\
0.96[0.65-1.43] \\
0.63[0.40-0.99] \\
0.93[0.63-1.37] \\
0.96[0.66-1.40] \\
1.28[0.90-1.81] \\
1.13[0.79-1.61] \\
0.87[0.60-1.26] \\
0.82[0.54-1.25]\end{array}$ & 0.135 & $\begin{array}{l}\text { Ref. } \\
0.97[0.66-1.43] \\
0.85[0.56-1.28] \\
0.80[0.52-1.21] \\
1.01[0.66-1.53] \\
0.56[0.37-0.93] \\
0.93[0.62-1.39] \\
0.81[0.55-1.18] \\
1.15[0.80-1.64] \\
1.06[0.74-1.53] \\
0.95[0.64-1.39] \\
0.90[0.59-1.38]\end{array}$ & 0.300 \\
\hline $\begin{array}{l}\text { Number of days since admission } \\
0 \text { days } \\
1 \text { day } \\
2 \text { days } \\
3 \text { days } \\
4 \text { days } \\
5 \text { days } \\
6 \text { days } \\
7 \text { days } \\
8 \text { days } \\
>8 \text { days }\end{array}$ & $\begin{array}{l}179 \\
366 \\
314 \\
307 \\
262 \\
184 \\
182 \\
157 \\
106 \\
606\end{array}$ & $\begin{array}{l}114(63.7 \%) \\
192(52.5 \%) \\
110(31.9 \%) \\
54(17.6 \%) \\
51(19.5 \%) \\
27(14.7 \%) \\
22(12.1 \%) \\
14(8.9 \%) \\
8(7.6 \%) \\
33(5.5 \%)\end{array}$ & $\begin{array}{l}5.15[3.48-7.62] \\
10.17[7.00-14.79] \\
6.29[4.23-9.37] \\
4.06[2.62-6.29] \\
4.66[2.99-7.25] \\
2.90[1.74-4.84] \\
2.87[1.67-4.94] \\
2.24[1.19-4.19] \\
1.51[0.69-3.27] \\
\text { Ref. }\end{array}$ & $<0.001$ & $\begin{array}{l}6.68[4.48-9.95] \\
13.38[9.14-19.59] \\
8.26[5.51-12.37] \\
5.25[3.37-8.17] \\
5.85[3.74-9.14] \\
3.55[2.12-5.95] \\
3.40[1.97-5.86] \\
2.61[1.39-4.90] \\
1.72[0.79-3.73] \\
\text { Ref. }\end{array}$ & $<0.001$ \\
\hline $\begin{array}{l}\text { Bed occupancy rate } \\
\qquad \begin{array}{c}0-85 \% \\
>85 \%\end{array}\end{array}$ & $\begin{array}{l}1,309 \\
1,354\end{array}$ & $\begin{array}{l}294(22.5 \%) \\
321(23.7 \%)\end{array}$ & $\begin{array}{l}\text { Ref. } \\
1.09 \text { [0.93-1.28] }\end{array}$ & 0.288 & $\begin{array}{l}\text { Ref. } \\
0.95 \text { [0.76-1.19] }\end{array}$ & 0.655 \\
\hline $\begin{array}{l}\text { Primary diagnosis } \\
\qquad \begin{array}{l}\text { Sepsis } \\
\text { Neonatal tetanus } \\
\text { NEC } \\
\text { Prematurity } \\
\text { HIE } \\
\text { Maternal-fetal infection } \\
\text { Respiratory syndromes } \\
\text { Other }\end{array}\end{array}$ & $\begin{array}{l}536 \\
110 \\
7 \\
293 \\
476 \\
50 \\
604 \\
587\end{array}$ & $\begin{array}{l}152(28.3 \%) \\
76(69.1 \%) \\
5(71.4 \%) \\
101(34.5 \%) \\
147(30.9 \%) \\
14(28.0 \%) \\
48(8.0 \%) \\
72(12.3 \%)\end{array}$ & $\begin{array}{l}2.77[2.00-3.83] . \\
4.98[3.47-7.14] \\
9.69[3.86-24.33] \\
1.92[1.36-2.70] \\
3.52[2.54-4.88] \\
2.02[1.11-3.66] \\
\text { Ref. } \\
1.65[1.15-2.38]\end{array}$ & $<0.001$ & $\begin{array}{l}3.43[2.47-4.76] \\
8.50[5.88-12.29] \\
11.65[4.56-29.76] \\
3.32[2.33-4.72] \\
4.13[2.97-5.75] \\
3.26[1.77-6.01] \\
\text { Ref. } \\
1.74[1.21-2.52]\end{array}$ & $<0.001$ \\
\hline
\end{tabular}

NEC - necrotizing enterocolitis, HIE - hypoxic-ischemic encephalopathy 
Table 4. Mortality rates per 1,000 person days $(95 \% \mathrm{Cl})$

for the primary diagnoses in Dera Murad Jamali (DMJ).

\begin{tabular}{|l|l|}
\hline Primary diagnosis & $\begin{array}{l}\text { Mortality rates per 1,000 } \\
\text { person days } \mathbf{( 9 5 \%} \mathbf{~ C l )}\end{array}$ \\
\hline Sepsis & $46.06(39.29-54.00)$ \\
Neonatal tetanus & $82.88(66.19-103.77)$ \\
NEC & $161.290(67.13-387.51)$ \\
\hline Prematurity & $31.92(26.27-38.80)$ \\
HIE & $58.63(49.88-68.92)$ \\
Maternal-fetal infection & $33.57(19.88-56.69)$ \\
Respiratory syndromes & $16.65(12.55-22.09)$ \\
Other & $27.55(21.87-34.71)$ \\
\hline
\end{tabular}

NEC - necrotizing enterocolitis, HIE - hypoxic-ischemic

encephalopathy

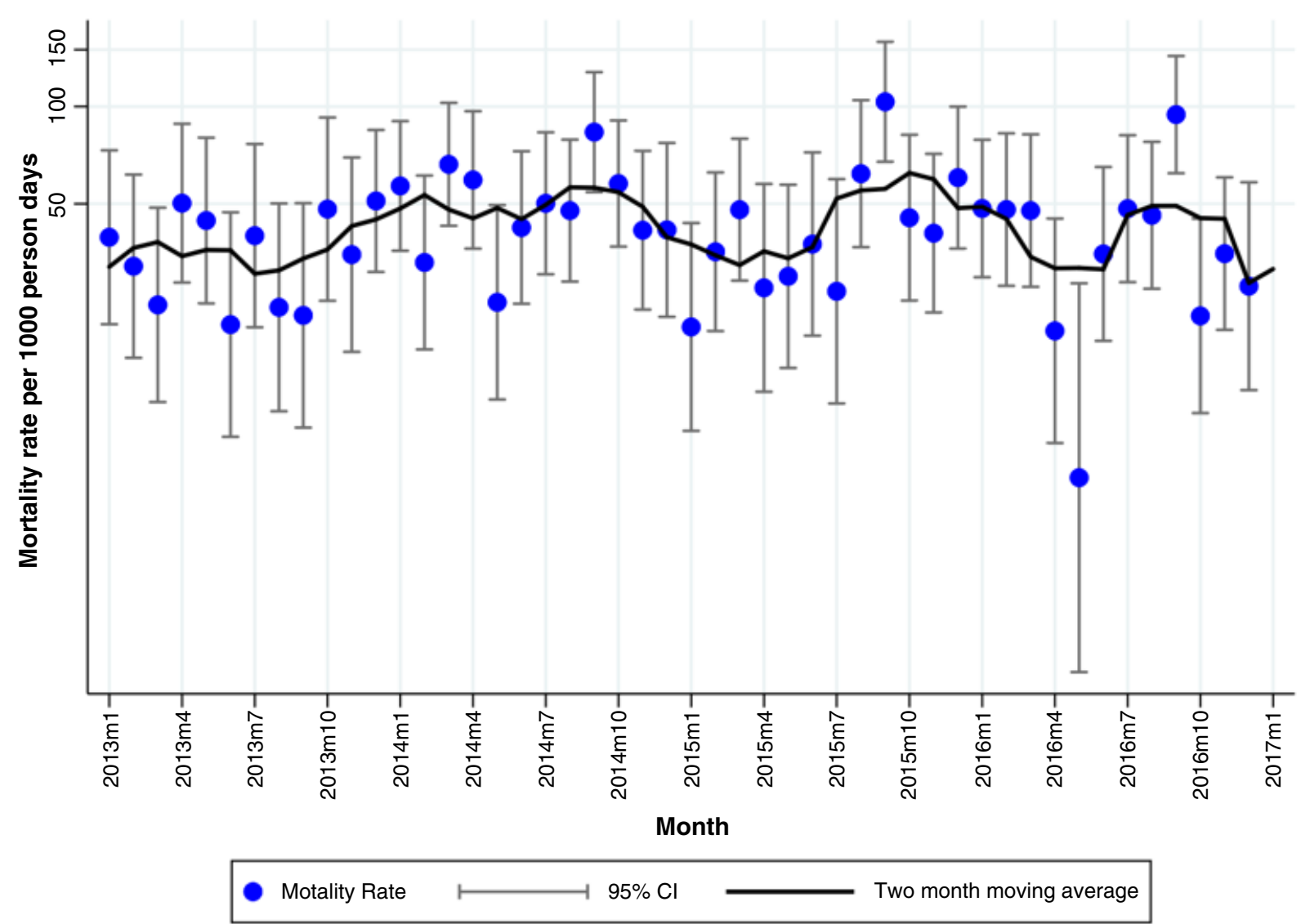

Figure 2. Monthly mortality rate (per 1,000-person days) and a $95 \%$ confidence interval and two months moving average smoothed morality rates for Chaman.

infants were more likely to die during the first 48 hours of admission, with the greatest risk at day 1 (24 to 48 hours since admission). This differs with other studies which suggest that the longer the stay in the hospital, the higher the chance to develop nosocomial infection leading to death ${ }^{7}$. Also, a longer stay in the hospital has been associated to severity of illness ${ }^{8}$.
We assume that the high mortality rate is not necessarily due to the care that MSF provides, but due to late presentation and critical state of the majority of patients in both hospitals. Anecdotally, MSF staff report that the patients are often treated with multiple antibiotics from other private health care centers. Neonatal care in private hospitals is expensive and when the financial 


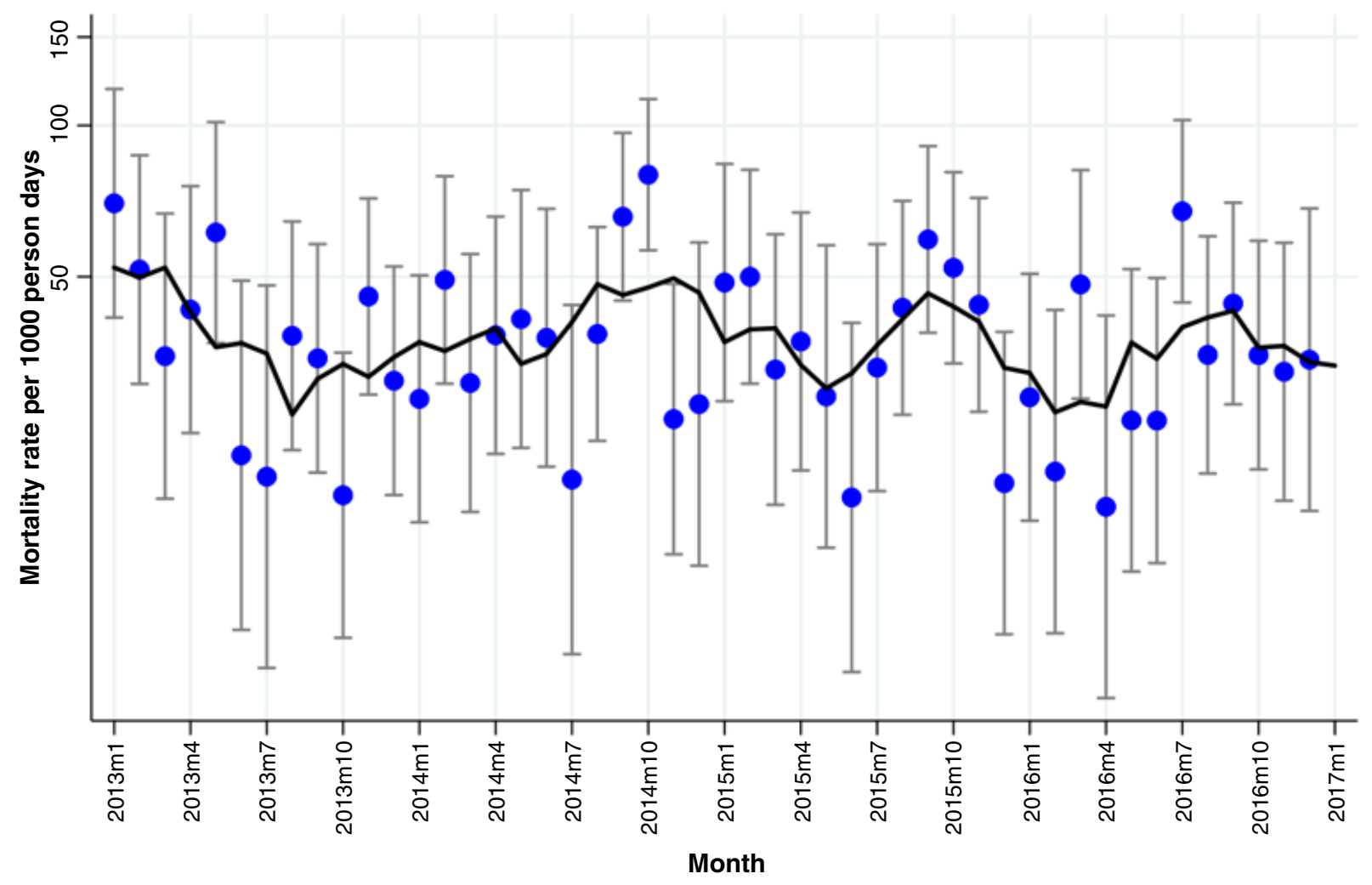

Motality Rate $\longmapsto 95 \% \mathrm{Cl}$

Two month moving average

Figure 3. Monthly mortality rate (per 1,000-person days) and a $95 \%$ confidence interval and two months moving average smoothed morality rates for Dera Murad Jamali (DMJ).

resources of families are exhausted, parents seek help in MSF hospitals. It is known that in developing countries the private sector is preferred over public sector ${ }^{9}$, however, the provided service is debatable. We did not have any information on date of on onset of symptoms to be able to evaluate whether late presentation played a role in high mortality rates early on in their admission. Nevertheless, literature states that infant survival is lower when there is a delay in seeking health care $^{10}$. Improving the health care seeking behavior will increase infant survival.

The male/female ratio in our study (1.60) was higher to the one found in the 2012-2013 DHS in Pakistan (1.04) ${ }^{3}$. This difference could be explained by son preference which has been described before in South $\mathrm{Asia}^{11}$ and/or by a reduced healthcare seeking behavior for girls by the parents in this region ${ }^{1,12}$, but we cannot be sure as this goes beyond the objective of the study.

We identified a seasonal pattern in the monthly mortality rate (per 1,000 person days) in hospitalized infants in Chaman and DMJ around September (Figure 2 and Figure 3). To our knowledge, the observed seasonal pattern has not been mentioned in the literature before. Two studies conducted in South Asia (Nepal and Bangladesh) among local populations have previously mentioned a seasonal pattern in mortality, but they found different seasonality patterns. In Nepal, the neonatal mortality rate was the highest between April and October, but the highest peak was observed in August (13). In Bangladesh, the peak of neonatal deaths was observed in November and for 1-4 year olds in the hot-wet season (July-September) ${ }^{13,14}$. However, the seasonality in mortality could be explained by seasonality of diseases. A study in Northern Pakistan showed that the highest prevalence of malaria parasites was found in infants after monsoon season (September-November) ${ }^{15}$. This similar peak (September-November) was also observed for dengue cases among admitted patients in the districts Shangla and Buner in Northern Pakistan ${ }^{16}$. In our IPD data there were no dengue diagnosis registered and the number of malaria diagnosis was very low (total 2013-2016: two in Chaman and 203 in DMJ), and did not show a seasonal pattern with increase in numbers in September.

The main limitation of this study was that it was a retrospective chart review, so there was no control in the use of data 
collection tools and on disease coding. We could also not explore the impact of infant age on mortality during this study. Despite the limitations, our study had the great strength of the large amount of observations around inpatient pediatric patients in this part of Pakistan, therefore the data included and the findings are highly relevant.

\section{Conclusion}

The first two days of admission are critical for infant survival in the MSF hospitals in Balochistan, an underserved area of Pakistan in terms of health care. We found an annual seasonal pattern in mortality rate by week and a male/female ratio in that was higher than the known male/female ratio of Pakistan. Further investigations are needed to establish i) if the cause of this male/female ratio differences is gender differences in access to care or an actual difference in burden of disease by gender and ii) the reasons behind these annual peaks in mortality rate by week. We recommend targeting efforts on increasing quality of care during the first days of admission and to allocate resources accordingly, and also taking into account the seasonal pattern.

\section{Ethical considerations}

This was a posteriori analysis of routinely collected clinical data; therefore, it was exempted from ethical board review. The MSF-OCA medical director gave his approval for this analysis. The data in the utilized datasets did not contain individual identifiers and it was password protected and only accessible by the research team.

\section{Data availability}

Underlying data

The nature of MSF operations and target populations are such that data collected often involves highly Sensitive Data. Recipients, who wish to access any MSF Datasets that include Personal Data and/or Human Samples, must secure ethical clearance from competent ethical authorities and of MSF ERB. If a reader wants to access the data he/she can find more information in the MSF Data Sharing Policy (http://hdl.handle. net/10144/306501).

\section{Grant information}

The author(s) declared that no grants were involved in supporting this work.

\section{Acknowledgements}

We would like to acknowledge the MSF and $\mathrm{MoH}$ staff in the DMJ and Chaman hospitals, they work hard every day to improve the health of these populations, without their effort this study would not have been possible. We would also like to thank the local populations for welcoming the MSF and MoH staff.
1. Lawn JE, Kerber K, Enweronu-Laryea C, et al:: $\mathbf{3 . 6}$ million neonatal deaths--what is progressing and what is not? Semin Perinatol. 2010; 34(6): 371-86. PubMed Abstract | Publisher Full Text

2. United Nations: The Millennium Development Goals Report. United Nations. 2015: 72

Reference Source

3. NIPS: Pakistan Demographic and Health Survey 2012-13. 2013; 392 Reference Source

4. Doctors without Borders, the Médecins Sans Frontières: International Activity Report 2015. 2016; 100 . Reference Source

5. Kupecz M: PAKISTAN'S BALOCH INSURGENCY: History, Conflict Drivers, and Regional Implications. Int Aff Rev. 2012. Reference Source

6. StataCorp: Stata Statistical Software: Release 14. 2015. 2015. Publisher Full Tex

7. Singh-Naz N, Sprague BM, Patel KM, et al.: Risk factors for nosocomial infection in critically ill children: A prospective cohort study. Crit Care Med. 1996; 24(5): 875-8.

PubMed Abstract | Publisher Full Text

8. Fiser DH, Tilford JM, Roberson PK: Relationship of illness severity and length of stay to functional outcomes in the pediatric intensive care unit: a multiinstitutional study. Crit Care Med. 2000; 28(4): 1173-79. PubMed Abstract | Publisher Full Text

9. Shaikh BT, Hatcher J: Health seeking behaviour and health service utilization in Pakistan: Challenging the policy makers. J Public Health (Oxf). 2005; 27(1) 49-54.

PubMed Abstract | Publisher Full Text
10. Lassi ZS, Middleton PF, Bhutta ZA, et al.: Strategies for improving health care seeking for maternal and newborn illnesses in low- and middle-income countries: A systematic review and meta-analysis. Glob Health Action. 2016; 9 : 31408.

PubMed Abstract | Publisher Full Text | Free Full Text

11. Gupta MD, Zhenghua J, Bohua L, et al:: Why is Son preference so persistent in East and South Asia? a cross-country study of China, India and the Republic of Korea. J Dev Stud. 2003; 40(2): 153-187. Publisher Full Text

12. Jehan I, Harris $\mathrm{H}$, Salat $\mathrm{S}$, et al:: Neonatal mortality, risk factors and causes: A prospective population-based cohort study in urban Pakistan. Bull World Health Organ. 2009; 87(2): 130-8.

PubMed Abstract | Publisher Full Text | Free Full Text

13. Hughes MM, Katz J, Mullany LC, et al.: Seasonality of birth outcomes in rural Sarlahi District, Nepal: a population-based prospective cohort. BMC Pregnancy Childbirth. 2014; 14: 310.

PubMed Abstract | Publisher Full Text | Free Full Text

14. Becker S, Weng S: Seasonal patterns of deaths in Matlab, Bangladesh. Int J Epidemiol. 1998; 27(5): 814-23. PubMed Abstract | Publisher Full Text

15. Zeb J, Sayed Khan M, Ullah H, et al.: Epidemiology of Plasmodium Species and Prevalence of Malaria on the Basis of Age, Sex, Area, Seasonality and Clinical Manifestation in the Population of District Lower Dir, Khyber Pakhtunkhwa, Pakistan. World J Zool. 2015; 10(2): 147-152. Reference Source

16. Khan J, Munir W, Khan B, et al.: Dengue outbreak 2013: Clinical profile of patients presenting at DHQ Burner and THQ Shangla, Khyber Pakhtunkhwa, Pakistan. Immun Dis. 2015; 3: a11. Reference Source 


\section{Open Peer Review}

\section{Current Peer Review Status:}

\section{Version 1}

Reviewer Report 06 September 2019

https://doi.org/10.5256/f1000research.21431.r51353

(C) 2019 Ismail S. This is an open access peer review report distributed under the terms of the Creative Commons Attribution License, which permits unrestricted use, distribution, and reproduction in any medium, provided the original work is properly cited.

\section{Sharif Ismail}

1 Department of Primary Care and Public Health, Imperial College London, London, UK

2 Department of Global Health and Development, London School of Hygiene and Tropical Medicine, London, UK

Thank you for the opportunity to review this paper, which presents data from two MSF hospitals in Pakistan to explore clinical factors associated with mortality among children admitted to these facilities. The analysis of seasonality in particular is an interesting and novel feature of this analysis although it is notable that differences between the two sites in this regard are not commented on in the manuscript.

There are some important ways in which the work could have been strengthened. For example:

1. The choice of a 7-month age cut off in defining the patient group is unusual as it corresponds neither to traditional definitions of the neonatal nor infant periods. It would have been helpful to know exactly why it would possible only according to the 7-month cut off and to have read a clearer explanation of the implications of this limitation for the analysis - and more on data limitations overall would have been useful.

2. Tables 2 and 4 aggregate diagnostic categories differently - why is this? Were no cases reported against the other categories? Separating out categories in the same way would have aided qualitative comparisons between the two sites.

3. The authors state that a pooled analysis across the two facilities was not practically useful to the teams. This is fine - but it would then have been helpful to include more data (if available) to test to account for observed differences - especially in mortality within the first 48 hours of admission. Were any triage assessment measures on admission available to include?

\section{Is the work clearly and accurately presented and does it cite the current literature?}


Is the study design appropriate and is the work technically sound?

Yes

Are sufficient details of methods and analysis provided to allow replication by others? Yes

If applicable, is the statistical analysis and its interpretation appropriate? Partly

Are all the source data underlying the results available to ensure full reproducibility? Yes

Are the conclusions drawn adequately supported by the results?

Yes

Competing Interests: No competing interests were disclosed.

Reviewer Expertise: Health systems and policy research.

I confirm that I have read this submission and believe that I have an appropriate level of expertise to confirm that it is of an acceptable scientific standard.

Reviewer Report 26 July 2019

https://doi.org/10.5256/f1000research.21431.r51351

(C) 2019 Leidman E. This is an open access peer review report distributed under the terms of the Creative Commons Attribution License, which permits unrestricted use, distribution, and reproduction in any medium, provided the original work is properly cited.

\section{Eva Leidman}

Center for Global Health, Centers for Disease Control and Prevention, Atlanta, GA, USA

The authors use routine data from two MSF hospitals in Pakistan to explore factors associated with in-hospital mortality among infants and neonates. As such the manuscript presents interesting analysis of an important research question. The authors nicely characterize the benefits and limitations of the retrospective data (e.g., lack of age data) used in the presented manuscript.

The manuscript would benefit from further details pertaining to the statistical analysis, as well as justification of the model selection. Additional details should include analysis performed to assure the assumptions of the Poisson model hold (e.g., measure of dispersion), and clarity on how the offset was modeled.

Additionally, as the key finding of the manuscript relates to differences in mortality associated with days since admission, (descriptive) analysis comparing characteristics of children with exits in 
the first 48 hours to the reference would be strengthen the manuscript, and help explore implications of the regression findings. Finally, global tests for month of admission (seasonality) appear only significant for Chaman (not DMJ). Discussing this distinction would also strengthen the manuscript.

Is the work clearly and accurately presented and does it cite the current literature? Yes

Is the study design appropriate and is the work technically sound?

Yes

Are sufficient details of methods and analysis provided to allow replication by others? Yes

If applicable, is the statistical analysis and its interpretation appropriate? Partly

Are all the source data underlying the results available to ensure full reproducibility? Yes

Are the conclusions drawn adequately supported by the results? Yes

Competing Interests: No competing interests were disclosed.

Reviewer Expertise: Epidemiology with focus on humanitarian emergencies.

I confirm that I have read this submission and believe that I have an appropriate level of expertise to confirm that it is of an acceptable scientific standard.

Reviewer Report 08 July 2019

https://doi.org/10.5256/f1000research.21431.r50282

(C) 2019 Shaikh B. This is an open access peer review report distributed under the terms of the Creative Commons Attribution License, which permits unrestricted use, distribution, and reproduction in any medium, provided the original work is properly cited.

\section{Babar Tasneem Shaikh \\ Health Services Academy, Islamabad, Pakistan}

This is an interesting approach to study such data in retrospective fashion. Findings on most common newborn or infants' illnesses and their outcomes (discharge or mortality) in Pakistan are well known and covered under various national surveys also. PDHS and MICS are two such examples besides various individual and organizational work published in recent years. 
The paper under consideration has used PDHS 2012-13 as a baseline and has attempted to make a case for two sites in Balochistan. The main thrust is that province under-performs vis-à-vis national statistics. This is not a new revelation and is a well-known and documented fact for many decades. With new PDHS 2017-18 released, this paper becomes redundant. Secondly, the causes of hospital admission or diagnoses found in infants are also chronologically known. Only thing which could have made this paper more interesting is adding the work of MSF which is being done at these two sites to address the issue of neonatal morbidity and mortality and the details of interventions which are being introduced at hospital or community level and then results shown with a significant difference made.

Is the work clearly and accurately presented and does it cite the current literature? Yes

Is the study design appropriate and is the work technically sound? Yes

Are sufficient details of methods and analysis provided to allow replication by others? Yes

If applicable, is the statistical analysis and its interpretation appropriate?

I cannot comment. A qualified statistician is required.

Are all the source data underlying the results available to ensure full reproducibility? Yes

Are the conclusions drawn adequately supported by the results?

Yes

Competing Interests: No competing interests were disclosed.

I confirm that I have read this submission and believe that I have an appropriate level of expertise to confirm that it is of an acceptable scientific standard, however I have significant reservations, as outlined above.

Author Response 15 Jul 2019

Babette van Deursen, Médecins Sans Frontières - Operational Centre Amsterdam, Amsterdam, The Netherlands

Dear Mr Shaikh,

Thank you for your revision of our article and your very useful comments. We believe that they have helped us to improve our paper.

To start with your comment on the PDHS 2017-2018, we would like to clarify that we were not aware of the new version when we submitted this manuscript. When we were drafting the manuscript last year, it was not published yet. So, your suggestion is highly pertinent 
and helpful. We think it is indeed better to use the newest results instead of the PDHS of 2013. We have amended accordingly. However, we still think our manuscript is not redundant since the PDHS does not include data on seasonality patterns in mortality, nor on time to death from admission. So our manuscript provides extra information on these two topics.

Regarding your point about describing the activities of MSF, we agree that it would be very interesting to elaborate more on this. Unfortunately it would be very difficult now for us to get these details as this was not included in our original request to the MSF research committee and to the team on the ground.

We believe that your comments and suggestions have helped us to improve the context information and the discussion of our results. We very much appreciate your time and comments.

Many thanks.

Yours sincerely, Babette van Deursen

\section{Adjustments:}

Introduction:

We can use the new data from PDHS 2017-2018 instead of the old PDHS 2013 on the mortality numbers.

Discussion:

New ratio male/female ratio for under-five 1.02 (PDHS 2017-2018).

Small difference between female/male treatment seeking behavior, especially for fever. However, these small differences do not fully explain our found difference in health seeking behavior between boys and girls.

Competing Interests: None competing interests. 
The benefits of publishing with F1000Research:

- Your article is published within days, with no editorial bias

- You can publish traditional articles, null/negative results, case reports, data notes and more

- The peer review process is transparent and collaborative

- Your article is indexed in PubMed after passing peer review

- Dedicated customer support at every stage

For pre-submission enquiries, contact research@f1000.com 